\title{
Comparison between 3D volumetric rendering and multiplanar slices on the reliability of linear measurements on CBCT images: an in vitro study
}

Thais Maria Freire FERNANDES ${ }^{1}$, Julie ADAMCZYK², Marcelo Lupion POLETI ${ }^{3}$, José Fernando Castanha HENRIQUES ${ }^{4}$, Bernard FRIEDLAND ${ }^{5}$, Daniela Gamba GARIB ${ }^{6}$

\author{
1- Department of Orthodontics. University of Northern Parana (UNOPAR), Londrina, PR, Brazil. \\ 2- Harvard School of Dental Medicine, Boston, MA, USA. \\ 3- Department of Radiology. University of Northern Parana (UNOPAR), Londrina, PR, Brazil. \\ 4- Department of Pediatric Dentistry, Orthodontics and Community Health, Bauru School of Dentistry, University of São Paulo, Bauru, SP, Brazil. \\ 5- Department of Oral Medicine, Infection \& Immunity. Harvard School of Dental Medicine, Boston, MA, USA. \\ 6- Department of Pediatric Dentistry, Orthodontics and Community Health, Bauru School of Dentistry; Hospital of Rehabilitation of Craniofacial Anomalies, \\ University of São Paulo, Bauru, SP, Brazil.
}

Corresponding address: Thais Maria Freire Fernandes - Universidade do Norte do Paraná (UNOPAR) - Rua João Huss, 450 Apto 104 - $86050-490$ - Londrina - PR - Phone/Fax: (43) 3371-7991 - e-mail: thaismaria@hotmail.com

Submitted: September 3, 2013 - Modification: February 17, 2014 - Accepted: April 30, 2014

\section{ABSTRACT}

\begin{abstract}
bjective: The purpose of this study was to determine the accuracy and reliability of two methods of measurements of linear distances (multiplanar 2D and tridimensional reconstruction 3D) obtained from cone-beam computed tomography (CBCT) with different voxel sizes. Material and Methods: Ten dry human mandibles were scanned at voxel sizes of 0.2 and $0.4 \mathrm{~mm}$. Craniometric anatomical landmarks were identified twice by two independent operators on the multiplanar reconstructed and on volume rendering images that were generated by the software Dolphin ${ }^{\circledR}$. Subsequently, physical measurements were performed using a digital caliper. Analysis of variance (ANOVA), intraclass correlation coefficient (ICC) and Bland-Altman were used for evaluating accuracy and reliability $(p<0.05)$. Results: Excellent intraobserver reliability and good to high precision interobserver reliability values were found for linear measurements from CBCT 3D and multiplanar images. Measurements performed on multiplanar reconstructed images were more accurate than measurements in volume rendering compared with the gold standard. No statistically significant difference was found between voxel protocols, independently of the measurement method. Conclusions: Linear measurements on multiplanar images of 0.2 and 0.4 voxel are reliable and accurate when compared with direct caliper measurements. Caution should be taken in the volume rendering measurements, because the measurements were reliable, but not accurate for all variables. An increased voxel resolution did not result in greater accuracy of mandible measurements and would potentially provide increased patient radiation exposure.
\end{abstract}

Keywords: Cone-beam computed tomography. Reliability. Mandible.

\section{INTRODUCTION}

Technological advances in three-dimensional (3D) imaging such as cone-beam computed tomography (CBCT) appear to offer significant advantages in both quality and quantity of data representing true anatomy $7,23-25,27$. The increased use of computed tomography in dentistry has also spurred the improvement of existing software designed primarily for dental use, as well as the development of new software ${ }^{9}$. However, it is necessary to select protocols and to assess the reliability and accuracy of landmark identification in 3D images 20 .

Development of 3D imaging into a practical and usable cephalometric method was hindered for many years by technologic limitations, high costs, and high radiation doses ${ }^{14}$. Advances in 
CBCT technology make its use feasible for specific indications, such as impacted teeth, craniofacial anomalies, airway and temporomandibular joint disorders. In these cases, CBCT images could be used for routine cephalometric purposes beyond the diagnostic purposes for which they were primarily taken. This has been extensively done for cephalometric measurements ${ }^{3,13}$, but to a much lesser extent for maxillofacial computed tomography imaging ${ }^{4,17}$. Whether CBCT should be used routinely in all orthodontic patients is still an open question.

A factor that could influence the use of $\mathrm{CBCT}$ is the voxel size. The voxel is the smallest unit of CT images and its size has an influence on image spatial resolution ${ }^{22}$. By decreasing the voxel size the image spatial resolution increases as there is a decrease in partial volume averaging ${ }^{8,22}$. On the other hand, by decreasing the voxel size, the scan time increases, as does the probability of patient movement ${ }^{22}$. Most significant however, increasing resolution increases patient dose. This is especially of concern in the case of younger individuals, who constitute the overwhelming majority of orthodontic patients. This issue of increased radiation dose to children, and specifically for orthodontic purposes, has caused widespread concern and has been the source of much discussion even in the lay literature ${ }^{5}$.

In order to verify the clinical reliability of measurements on multiplanar sections and 3D reconstructions derived from $\mathrm{CBCT}$, it is also necessary to evaluate the measurements using anatomic landmarks without the use of metallic markers. The most recent studies involving CBCT scans have shown reproducibility and accuracy of cephalometric measurements performed on lateral cephalograms reformatted from CBCT images ${ }^{17}$ or in 3D-CBCT images ${ }^{4,18}$. However, most of the studies used radiopaque markers ${ }^{6,8}$ and these might have an influence on the accuracy and reproducibility of the measurements. The presence of metallic markers eliminates errors from landmark identification because metallic landmarks can be easily identified and located with a high degree of accuracy and precision. The absence of metallic markers simulates the real clinical situation.

For these reasons, the aim of this study was to verify the influence of voxel size on the accuracy and reproducibility of linear measurements of the mandible performed without metallic markers on 3D CBCT images, comparing multiplanar sections and $3 \mathrm{D}$ rendering images.

\section{MATERIAL AND METHODS}

Approval for this study was received from the Ethics Committee at the University of São Paulo, Bauru, Brazil. Ten dry adult human mandibles, selected from the collection of dry skulls of the Department of Anatomy from the Bauru School of Dentistry were scanned. To fit the inclusion criteria, the mandibles had to be well preserved with no large metallic restorations on the teeth, in order to avoid scattering and artifacts. The sample size of each group was calculated based on an alpha significance level of 0.05 and beta of 0.2 to achieve $80 \%$ of power ${ }^{8}$.

To provide soft-tissue equivalent attenuation, each dry mandible was placed in a dental wax box filled with water. The mandibles were positioned with the mandibular plane parallel and the midsagittal plane perpendicular to the floor, in accordance with the manufacturer's instructions for performing the scans in the clinical setting. The CBCT images were acquired using the i-CAT Classic 3D Dental Imaging System (i-CAT Classic, Imaging Sciences International, Hatfield, PA, USA). Each mandible was scanned twice: once with a 0.20 voxel resolution ( $36.12 \mathrm{mAs}, 40 \mathrm{sec}$, FOV of $8 \mathrm{~cm}, 120$ $\mathrm{Kv})$ and once with a 0.40 voxel resolution (18.45 $\mathrm{mAs}, 20 \mathrm{sec}$, FOV of $8 \mathrm{~cm}, 120 \mathrm{Kv}$ ).

CBCT data were exported in DICOM (Digital Imaging and Communication in Medicine) multi-file format and imported into Dolphin ${ }^{\circledR} 11.5$ software (Dolphin Imaging \& Management Solutions, Patterson Technology, Chatsworth, CA, USA). A

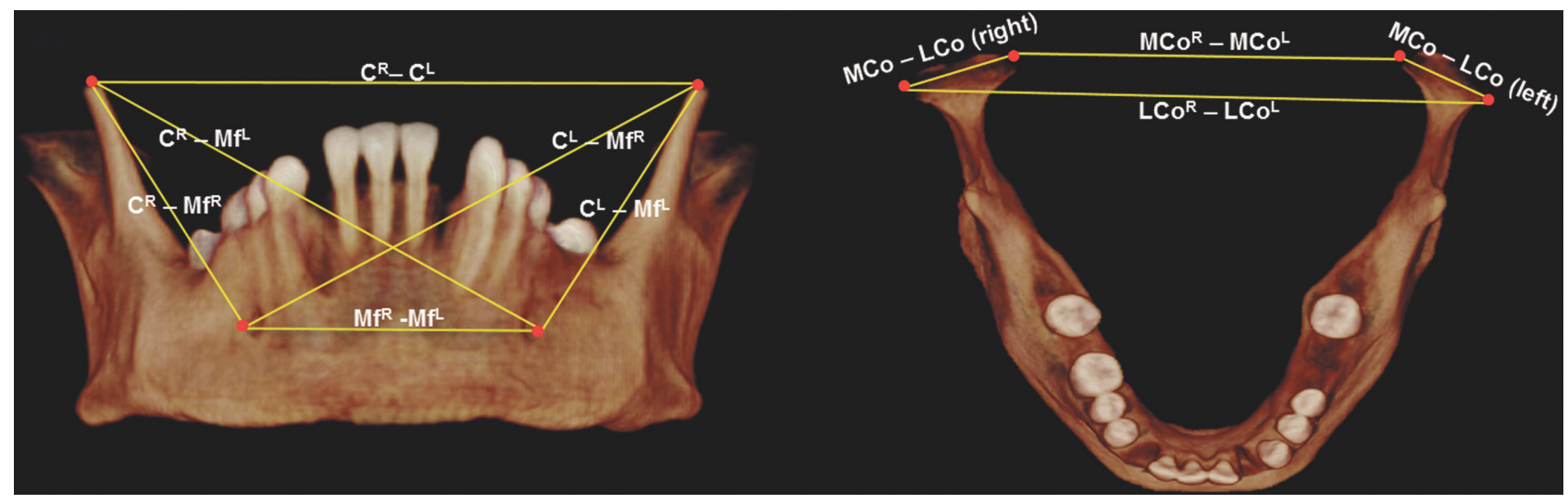

Figure 1- Frontal (left) and sagittal (right) views of mandible showing the points 


\begin{tabular}{|c|c|c|}
\hline Name (Abbreviation) & Definition (Point) & $\begin{array}{c}\text { СВСТ Reference in the multiplanar } \\
\text { view }\end{array}$ \\
\hline Coronoid $\left(C^{R}\right)$ & $\begin{array}{l}\text { Located at the upper limit of the } \\
\text { coronoid process on the right side }\end{array}$ & $\begin{array}{l}\text { Move green line upward and downward } \\
\text { in the axial slice and/or green line to the } \\
\text { right and left in the sagittal slice to find } \\
\text { the point located at the upper limit of the } \\
\text { coronoid process }\end{array}$ \\
\hline Coronoid $\left(\mathrm{C}^{\mathrm{L}}\right)$ & $\begin{array}{l}\text { Located at the upper limit of the } \\
\text { coronoid process on the left side }\end{array}$ & Similar to $\mathrm{CR}$, but on the left side \\
\hline Mental Foramen $\left(\mathrm{Mf}^{\mathrm{R}}\right)$ & $\begin{array}{l}\text { Located at the most lower and } \\
\text { posterior limit of the mental foramen } \\
\text { on the right side }\end{array}$ & $\begin{array}{c}\text { Move green line upward and downward } \\
\text { in the axial slice and/or green line to the } \\
\text { right and left in the sagittal slice to find } \\
\text { the most lower and posterior limit of the } \\
\text { mental foramen }\end{array}$ \\
\hline Mental Foramen $\left(\mathrm{Mf}^{\llcorner}\right)$ & $\begin{array}{l}\text { Located at the most lower and } \\
\text { posterior limit of the mental foramen } \\
\text { on the left side }\end{array}$ & Similar to MfR, but on the left side \\
\hline Lateral mandibular condyle $\left(\mathrm{LCo}^{\mathrm{R}}\right)$ & $\begin{array}{l}\text { Located at the most lateral limit of } \\
\text { the right mandibular condyle viewed } \\
\text { coronally }\end{array}$ & $\begin{array}{l}\text { Move blue line upward and downward in } \\
\text { the coronal or sagittal slice until the limit } \\
\text { of condyle appears }\end{array}$ \\
\hline Lateral mandibular condyle ( $\left.\mathrm{LCo}^{\llcorner}\right)$ & $\begin{array}{l}\text { Located at the most lateral limit of } \\
\text { the left mandibular condyle viewed } \\
\text { coronally }\end{array}$ & Similar to LCoR, but on the left side \\
\hline Medial mandibular condyle $\left(\mathrm{MCo}^{\mathrm{R}}\right)$ & $\begin{array}{c}\text { Located in the most medial limit of } \\
\text { the right mandibular condyle viewed } \\
\text { coronally }\end{array}$ & $\begin{array}{l}\text { Move blue line upward and downward in } \\
\text { the coronal or sagittal slice until the limit } \\
\text { of condyle appears }\end{array}$ \\
\hline Medial mandibular condyle (MCo $\left.{ }^{\llcorner}\right)$ & $\begin{array}{l}\text { Located in the most medial limit of } \\
\text { the left mandibular condyle viewed } \\
\text { coronally }\end{array}$ & Similar to MCoR, but on the left side \\
\hline
\end{tabular}

Figure 2- Points. Reference in the anatomical view and in the cone-beam computed tomography (CBCT) images

\begin{tabular}{|c|c|c|}
\hline & Measurement & Definition \\
\hline 1 & $C^{R}-C^{L}$ & Inter-coronoid width. Linear distance between coronoid points \\
\hline 2 & $M f^{R}-M f^{L}$ & Inter-mental foramen width. Linear distance between mental foramen points \\
\hline 3 & $C^{R}-M f^{R}$ & Linear distance between right coronoid point and right mental foramen \\
\hline 4 & $\mathrm{C}^{\mathrm{R}}-\mathrm{Mf}^{\mathrm{L}}$ & Linear distance between right coronoid point and left mental foramen \\
\hline 5 & $C^{L}-M f^{L}$ & Linear distance between left coronoid point and left mental foramen \\
\hline 6 & $C^{L}-M f^{R}$ & Linear distance between left coronoid point and right mental foramen \\
\hline 7 & MCo - Lco (right) & $\begin{array}{l}\text { Condylar width. Linear distance between medial mandibular condyle and lateral } \\
\text { mandibular condyle in the right size }\end{array}$ \\
\hline 8 & MCo - Lco (left) & $\begin{array}{l}\text { Condylar width. Linear distance between medial mandibular condyle and lateral } \\
\text { mandibular condyle in the left size }\end{array}$ \\
\hline 9 & $\mathrm{LCo}^{\mathrm{R}}-\mathrm{LCo}^{\mathrm{L}}$ & $\begin{array}{l}\text { Maximum lateral intercondylar distance. Linear distance between lateral } \\
\text { mandibular condyles }\end{array}$ \\
\hline 10 & $M \mathrm{MCo}^{\mathrm{R}}-\mathrm{MCo}^{\mathrm{L}}$ & $\begin{array}{l}\text { Maximum medial intercondylar distance. Linear distance between medial } \\
\text { mandibular condyles }\end{array}$ \\
\hline
\end{tabular}

Figure 3- Definitions of mandibular linear measurements 
computer A505-S6975 (Satellite, Toshiba, Tokyo, Japan) with a dedicated $512-\mathrm{MB}$ video card on a 17-in CrystalBrite LCD flat-panel color screen with a maximum resolution of $1440 \times 900$ pixels was used.

\section{Image measurements}

Measurements were made separately on the multiplanar sections (2D) and on $3 D$ rendering images display window of Dolphin 3D. The multiplanar window displays the sagittal, coronal and axial slices, as well as the 3D rendered image. It was possible to visualize the 3 projections and the $3 \mathrm{D}$ rendered image together or choose one of the four images in full screen.

Linear measurements of 3D coordinates were obtained using several craniometric anatomic landmarks (Figure 1). For multiplanar groups, each landmark (Figure 2) was identified and marked on the three orthogonal slices simultaneously (axial, sagittal and coronal). The corresponding linear measurements (Figure 3) were determined electronically with the "Measurement" tool on the sectional images. For performing the linear measurements which landmarks were not located in the same sectional image, as $C^{L}-M f^{L}$, the first mark of a line was performed in the sectional image showing the first landmark and the second mark was performed on a different section showing the second landmark. As the volume rendering was reoriented, the positions of the landmarks were verified in the axial, sagittal and coronal slices and, if necessary, relocated.

For 3D rendering images, the landmarks were identified directly on the surface for 3D images. Corresponding linear measurements were determined with a line between the landmarks. The measurements were performed twice by 2 blinded independent examiners (TMFF and JA). The time interval between the two measurements was 15 days.

The physical measurements of the dry mandibles were obtained with a high-precision digital caliper (Mitutoyo, Mitutoyo Sul Americana, Suzano, SP, Brazil), identical to those used in similar studies ${ }^{23}$. In this initial study, we selected landmarks that are relatively easy to identify. Points were identified and measured with the digital caliper. Linear measurements were identified on two occasions, one month apart, by one operator (MLP). The mean of the two measurements of each distance was calculated and used as the gold standard to evaluate the accuracy of the CBCT 3D images. The measurements were grouped into five groups: physical measurements (G1); measurements performed on multiplanar slices with $0.20 \mathrm{~mm}$ voxel size (G2); measurements performed on multiplanar slices with $0.40 \mathrm{~mm}$ voxel size (G3); measurements performed on 3D images with voxel size of $0.20 \mathrm{~mm}$
(G4) and measurements performed on 3D images with voxel size of $0.40 \mathrm{~mm}$ (G5).

\section{Statistical analyses}

Intraclass correlation and Bland-Altman test was used to evaluate the intra- and interobserver reliability. Analysis of variance for repeated measures (ANOVA) and Dunnett's test were used to compare the groups on CВCT images and the physical measurements. Results were considered significant at $p<0.05$. All tests were performed with Statistica software 6.0 (Statistica for Windows; Statsoft, Tulsa, Ok, USA) and SPSS version 10 (SPSS, SPSS Inc., Chicago, IL, USA).

\section{RESULTS}

Intra- and interobserver reproducibility are shown in Table 1 . The measurements for investigator 1 showed excellent reliability with intraclass correlation coefficients (ICC) ranging from 0.93 to 1 (ICC average G2:0.97; G3:0.97; G4:0.98 and G5:0.98). Additionally, the mean absolute differences between the first and second measurements were less than $0.40 \mathrm{~mm}$ (mean average difference $\mathrm{G} 2: 0.11 \mathrm{~mm}$ and $\mathrm{G} 3: 0.02 \mathrm{~mm}$ ) for multiplanar images and less than $0.64 \mathrm{~mm}$ (mean average difference G4:0.14 mm and G5:0.03 $\mathrm{mm}$ ) for 3D model images. For Investigator 2, the results also showed excellent reliability, with ICC coefficients ranging from 0.88 to 0.99 (ICC average - G2:0.96; G3:0.95; G4:0.97 and G5:0.97).

CBCT multiplanar reconstruction measurements showed good to high interobserver reliability with ICC ranging from 0.63 to 0.99 (mean average $\mathrm{G} 2=0.86$ and $\mathrm{G} 3=0.87$ ) with the absolute differences between the first and second measurements ranging for 0 to $2.12 \mathrm{~mm}$ (mean average difference G2:-0.34 mm and G3:-0.49 mm, Table 1). For 3D reconstruction measurements, independently of the voxel size (G4 or G5), most of the variables presented good to high interobserver reliability, with the exception of inter-mental foramen width $\left(M f^{R}-M f^{L}\right)$ that had fair reliability on $0.2 \mathrm{~mm}$ voxel images $(\mathrm{G} 4=0.26)$ and moderate reliability for 0.4 voxel size $(\mathrm{G} 5=0.45)$.

The mean values and standard deviations of the physical measurements and of the CBCT measurements for all groups are presented in Table 2. Two variables ( $M f^{R}-M f^{L}$ and $\left.C^{R}-M f^{L}\right)$ at groups $\mathrm{G} 2$ and $\mathrm{G} 3$ were significantly smaller than physical measurements (G1). For 3D rendering images (G4 and G5), only two variables out of 10 were not significantly smaller than the physical measurements. No significant difference was found between the voxel size both for 3D rendering and multiplanar sections. 
Table 1- Intraobserver and interobserver variation for each group and analysis methods [intraclass correlation coefficient (ICC) and Bland-Altman]

\begin{tabular}{|c|c|c|c|c|c|c|c|c|c|c|c|c|c|c|c|c|c|}
\hline \multirow{3}{*}{ Variable } & & & \multicolumn{7}{|c|}{ Multiplanar images } & \multicolumn{8}{|c|}{ 3D model images } \\
\hline & & & \multicolumn{3}{|c|}{ G2 } & \multicolumn{4}{|c|}{ G3 } & \multicolumn{4}{|c|}{ G4 } & \multicolumn{4}{|c|}{ G5 } \\
\hline & & & \multicolumn{3}{|c|}{0.2 voxel $(n=10)$} & \multicolumn{4}{|c|}{0.4 voxel $(n=10)$} & \multicolumn{4}{|c|}{0.2 voxel $(n=10)$} & \multicolumn{4}{|c|}{0.4 voxel $(n=10)$} \\
\hline \multicolumn{18}{|c|}{ Intraobserver } \\
\hline & $\begin{array}{c}\text { Obser } \\
\text { ver }\end{array}$ & $\overline{A D}$ & SD & $\begin{array}{c}95 \% \\
\mathrm{Cl}\end{array}$ & TCC & $\overline{A D}$ & SD & $\begin{array}{c}95 \% \\
\mathrm{Cl}\end{array}$ & TCC & $\overline{A D}$ & SD & $\begin{array}{c}95 \% \\
\mathrm{Cl}\end{array}$ & TCC & $\overline{A D}$ & SD & $\begin{array}{c}95 \% \\
\mathrm{Cl}\end{array}$ & TCC \\
\hline \multirow[t]{2}{*}{$C^{R}-C^{L}$} & 1 & 0.01 & 0.36 & $\begin{array}{c}-0.69 \\
0.71\end{array}$ & 1 & -0.01 & 0.15 & $\begin{array}{c}-0.31 \\
0.29\end{array}$ & 1 & 0.12 & 0.67 & $\begin{array}{c}-1.20 \\
1.44\end{array}$ & 0.99 & 0.18 & 0.77 & $\begin{array}{c}-1.34 \\
1.70\end{array}$ & 0.98 \\
\hline & 2 & -0.41 & 0.75 & $\begin{array}{c}-1.89 \\
1.07\end{array}$ & 0.98 & -0.68 & 0.75 & $\begin{array}{c}-2.16 \\
0.80\end{array}$ & 0.97 & 0.17 & 0.87 & $\begin{array}{c}-1.54 \\
1.88\end{array}$ & 0.98 & 0.46 & 0.73 & $\begin{array}{c}-0.98 \\
1.90\end{array}$ & 0.98 \\
\hline \multirow[t]{2}{*}{$M f^{R}-M f^{L}$} & 1 & -0.13 & 0.46 & $\begin{array}{c}-1.03 \\
0.77\end{array}$ & 0.99 & -0.19 & 0.49 & $\begin{array}{c}-1.14 \\
0.76\end{array}$ & 0.98 & 0.17 & 0.72 & $\begin{array}{c}-1.25 \\
1.59\end{array}$ & 0.96 & -0.21 & 0.49 & $\begin{array}{c}-1.17 \\
0.75\end{array}$ & 0.98 \\
\hline & 2 & -0.30 & 1.18 & $\begin{array}{c}-2.16 \\
2.01\end{array}$ & 0.93 & -0.08 & 0.68 & $\begin{array}{c}-1.41 \\
1.25\end{array}$ & 0.97 & -0.21 & 0.82 & $\begin{array}{c}-1.82 \\
1.40\end{array}$ & 0.96 & -0.03 & 1.33 & $\begin{array}{c}-2.63 \\
2.57\end{array}$ & 0.92 \\
\hline \multirow[t]{2}{*}{$C^{R}-M f^{R}$} & 1 & -0.04 & 1.09 & $\begin{array}{c}-2.18 \\
2.10\end{array}$ & 0.97 & 0.31 & 0.67 & $\begin{array}{c}-0.99 \\
1.61\end{array}$ & 0.98 & 0.64 & 0.78 & $\begin{array}{c}-0.90 \\
2.18\end{array}$ & 0.98 & 0.26 & 0.81 & $\begin{array}{c}-1.32 \\
1.84\end{array}$ & 0.98 \\
\hline & 2 & -0.58 & 1.21 & $\begin{array}{c}-2.95 \\
1.79\end{array}$ & 0.95 & -0.92 & 0.97 & $\begin{array}{c}-2.81 \\
0.97\end{array}$ & 0.96 & 0.48 & 0.92 & $\begin{array}{c}-1.33 \\
2.29\end{array}$ & 0.97 & 0.42 & 0.75 & $\begin{array}{c}-1.04 \\
1.88\end{array}$ & 0.98 \\
\hline \multirow[t]{2}{*}{$C^{R}-M f^{L}$} & 1 & 0.19 & 0.84 & $\begin{array}{c}-1.46 \\
1.84\end{array}$ & 0.99 & 0.24 & 0.90 & $\begin{array}{c}-1.53 \\
2.01\end{array}$ & 0.97 & 0.39 & 0.67 & $\begin{array}{c}-0.93 \\
1.71\end{array}$ & 0.98 & 0.10 & 0.70 & $\begin{array}{c}-1.28 \\
1.48\end{array}$ & 0.99 \\
\hline & 2 & -0.66 & 0.81 & $\begin{array}{c}-2.24 \\
0.92\end{array}$ & 0.97 & -0.81 & 1.27 & $\begin{array}{c}-3.30 \\
1.68\end{array}$ & 0.94 & 0.10 & 0.73 & $\begin{array}{c}-1.34 \\
1.54\end{array}$ & 0.99 & 0.63 & 0.85 & $\begin{array}{c}-1.03 \\
2.29\end{array}$ & 0.97 \\
\hline \multirow[t]{2}{*}{$\mathrm{C}^{\mathrm{L}}-\mathrm{Mf}^{\mathrm{L}}$} & 1 & 0.40 & 1.22 & $\begin{array}{l}-2.0 \\
2.80\end{array}$ & 0.95 & 0.05 & 1.40 & $\begin{array}{c}-2.68 \\
2.78\end{array}$ & 0.93 & 0.04 & 1.00 & $\begin{array}{c}-1.93 \\
2.01\end{array}$ & 0.96 & 0.26 & 1.06 & $\begin{array}{c}-1.83 \\
2.35\end{array}$ & 0.95 \\
\hline & 2 & -1.05 & 0.90 & $\begin{array}{c}-2.82 \\
0.72\end{array}$ & 0.91 & -0.29 & 1.01 & $\begin{array}{c}-2.27 \\
1.69\end{array}$ & 0.95 & -0.09 & 0.61 & $\begin{array}{c}-1.28 \\
1.10\end{array}$ & 0.99 & 0.41 & 0.68 & $\begin{array}{c}-0.92 \\
1.74\end{array}$ & 0.97 \\
\hline \multirow[t]{2}{*}{$C^{L}-M f^{R}$} & 1 & 0.12 & 1.40 & $\begin{array}{c}-2.62 \\
2.86\end{array}$ & 0.94 & -0.04 & 1.13 & $\begin{array}{c}-2.27 \\
2.19\end{array}$ & 0.95 & 0.09 & 0.90 & $\begin{array}{c}-1.67 \\
1.85\end{array}$ & 0.97 & 0.09 & 0.73 & $\begin{array}{c}-1.35 \\
1.53\end{array}$ & 0.98 \\
\hline & 2 & -0.65 & 0.88 & $\begin{array}{c}-2.36 \\
1.06\end{array}$ & 0.96 & -0.69 & 0.72 & $\begin{array}{c}-2.10 \\
0.72\end{array}$ & 0.96 & -0.02 & 0.99 & $\begin{array}{c}-1.96 \\
1.92\end{array}$ & 0.97 & 0.06 & 1.01 & $\begin{array}{c}-1.93 \\
2.05\end{array}$ & 0.97 \\
\hline \multirow[t]{2}{*}{ MCo - LCo (right) } & 1 & -0.03 & 0.39 & $\begin{array}{c}-0.80 \\
0.74\end{array}$ & 0.98 & -0.07 & 0.40 & $\begin{array}{c}-0.84 \\
0.70\end{array}$ & 0.98 & 0.14 & 0.28 & $\begin{array}{c}-0.42 \\
0.70\end{array}$ & 0.99 & -0.03 & 0.45 & $\begin{array}{c}-0.91 \\
0.85\end{array}$ & 0.98 \\
\hline & 2 & 0.26 & 0.47 & $\begin{array}{c}-0.66 \\
1.18\end{array}$ & 0.97 & 0.18 & 0.71 & $\begin{array}{c}-1.22 \\
1.58\end{array}$ & 0.95 & 0.77 & 0.54 & $\begin{array}{c}-0.29 \\
1.83\end{array}$ & 0.90 & 0.68 & 0.55 & $\begin{array}{c}-0.40 \\
1.76\end{array}$ & 0.92 \\
\hline \multirow[t]{2}{*}{ MCo - LCo (left) } & 1 & 0.39 & 0.44 & $\begin{array}{c}-0.47 \\
1.25\end{array}$ & 0.94 & -0.38 & 0.53 & $\begin{array}{c}-1.42 \\
0.66\end{array}$ & 0.93 & 0.01 & 0.35 & $\begin{array}{c}-0.67 \\
0.69\end{array}$ & 0.98 & -0.05 & 0.53 & $\begin{array}{c}-1.10 \\
1.00\end{array}$ & 0.95 \\
\hline & 2 & -0.05 & 0.53 & $\begin{array}{c}-1.08 \\
0.99\end{array}$ & 0.95 & 0.30 & 0.81 & $\begin{array}{c}-1.29 \\
1.89\end{array}$ & 0.88 & -0.08 & 0.43 & $\begin{array}{c}-0.93 \\
0.77\end{array}$ & 0.98 & 0.14 & 0.33 & $\begin{array}{c}-0.50 \\
0.78\end{array}$ & 0.98 \\
\hline \multirow[t]{2}{*}{$\mathrm{LCo}^{\mathrm{R}}-\mathrm{LCo}^{\mathrm{L}}$} & 1 & 0.30 & 0.38 & $\begin{array}{c}-0.34 \\
0.94\end{array}$ & 0.99 & -0.22 & 0.50 & $\begin{array}{c}-1.22 \\
0.78\end{array}$ & 0.99 & -0.03 & 0.31 & $\begin{array}{c}-0.65 \\
0.59\end{array}$ & 1 & -0.15 & 0.70 & $\begin{array}{c}-1.52 \\
1.22\end{array}$ & 0.99 \\
\hline & 2 & -0.30 & 0.70 & $\begin{array}{c}-1.09 \\
1.69\end{array}$ & 0.98 & 0.15 & 0.67 & $\begin{array}{c}-1.15 \\
1.45\end{array}$ & 0.99 & 0.77 & 0.53 & $\begin{array}{c}-0.28 \\
1.82\end{array}$ & 0.97 & 0.78 & 0.53 & $\begin{array}{c}-0.27 \\
1.83\end{array}$ & 0.97 \\
\hline $\mathrm{MCo}^{\mathrm{R}}-\mathrm{MCo}^{\mathrm{L}}$ & 1 & -0.07 & 0.35 & $\begin{array}{c}-0.76 \\
0.62\end{array}$ & 0.99 & 0.08 & 0.54 & $\begin{array}{c}-0.98 \\
1.14\end{array}$ & 0.98 & -0.22 & 0.35 & $\begin{array}{c}-0.91 \\
0.47\end{array}$ & 0.99 & -0.12 & 0.50 & $\begin{array}{c}-1.11 \\
0.87\end{array}$ & 0.99 \\
\hline & 2 & -0.33 & 0.51 & $\begin{array}{c}-1.34 \\
0.68\end{array}$ & 0.98 & -0.62 & 0.35 & $\begin{array}{c}-1.31 \\
0.07\end{array}$ & 0.97 & -0.08 & 0.35 & $\begin{array}{c}-0.78 \\
0.62\end{array}$ & 0.99 & -0.05 & 1.29 & $\begin{array}{c}-0.62 \\
0.52\end{array}$ & 0.99 \\
\hline Total & 1 & 0.11 & & & 0.97 & 0.02 & & & 0.97 & 0.14 & & & 0.98 & 0.03 & & & 0.98 \\
\hline & 2 & -0.41 & & & 0.96 & -0.35 & & & 0.95 & 0.18 & & & 0.97 & 0.35 & & & 0.97 \\
\hline & & & & & & & erobse & rver & & & & & & & & & \\
\hline$C^{R}-C^{L}$ & $1 \times 2$ & -0.54 & 0.98 & $\begin{array}{c}-2.46 \\
1.38\end{array}$ & 0.96 & 0.00 & 0.49 & $\begin{array}{c}-0.95 \\
0.96\end{array}$ & 0.99 & -0.11 & 0.88 & $\begin{array}{c}-1.84 \\
1.63\end{array}$ & 0.98 & -0.15 & 0.56 & $\begin{array}{c}-1.25 \\
0.95\end{array}$ & 0.99 \\
\hline$M f^{R}-M f^{L}$ & $1 \times 2$ & 1.00 & 0.61 & $\begin{array}{c}-0.20 \\
2.19\end{array}$ & 0.91 & 0.94 & 0.54 & $\begin{array}{c}-0.12 \\
1.99\end{array}$ & 0.92 & 3.59 & 1.49 & $\begin{array}{l}0.66 \\
6.51\end{array}$ & 0.26 & 3.25 & 1.45 & $\begin{array}{l}0.38 \\
6.09\end{array}$ & 0.45 \\
\hline$C^{R}-M f^{R}$ & $1 \times 2$ & -1.20 & 1.18 & $\begin{array}{c}-3.51 \\
1.15\end{array}$ & 0.93 & -1.49 & 1.09 & $\begin{array}{c}-3.63 \\
0.64\end{array}$ & 0.90 & -2.42 & 0.80 & $\begin{array}{l}-3.99 \\
-0.84\end{array}$ & 0.84 & -2.56 & 0.66 & $\begin{array}{l}-3.86 \\
-1.26\end{array}$ & 0.82 \\
\hline$C^{R}-M f^{L}$ & $1 \times 2$ & 0.63 & 1.05 & $\begin{array}{c}-1.45 \\
2.70\end{array}$ & 0.97 & 0.06 & 0.80 & $\begin{array}{c}-1.51 \\
1.64\end{array}$ & 0.98 & 0.07 & 1.20 & $\begin{array}{c}-2.30 \\
2.43\end{array}$ & 0.96 & -0.34 & 0.57 & $\begin{array}{c}-1.46 \\
0.79\end{array}$ & 0.99 \\
\hline$C^{L}-M f^{L}$ & $1 \times 2$ & -1.09 & 1.34 & $\begin{array}{c}-3.72 \\
1.53\end{array}$ & 0.89 & -1.07 & 0.94 & $\begin{array}{c}-2.91 \\
0.79\end{array}$ & 0.92 & -2.42 & 1.38 & $\begin{array}{c}-5.13 \\
0.30\end{array}$ & 0.70 & -2.47 & 1.06 & $\begin{array}{l}-4.56 \\
-0.37\end{array}$ & 0.69 \\
\hline$C^{L}-M f^{R}$ & $1 \times 2$ & 0.40 & 0.60 & $\begin{array}{c}-0.78 \\
1.59\end{array}$ & 0.98 & -0.79 & 0.81 & $\begin{array}{c}-0.79 \\
2.38\end{array}$ & 0.95 & 0.07 & 0.68 & $\begin{array}{c}-1.28 \\
1.41\end{array}$ & 0.98 & 0.10 & 0.58 & $\begin{array}{c}-1.05 \\
1.24\end{array}$ & 0.99 \\
\hline MCo - LCo (right) & $1 \times 2$ & -1.77 & 0.54 & $\begin{array}{l}-2.83 \\
-0.71\end{array}$ & 0.69 & -1.84 & 0.50 & $\begin{array}{l}-2.83 \\
-0.86\end{array}$ & 0.67 & -0.18 & 0.84 & $\begin{array}{c}-1.83 \\
1.46\end{array}$ & 0.92 & -0.49 & 0.46 & $\begin{array}{c}-1.40 \\
0.41\end{array}$ & 0.95 \\
\hline MCo - LCo (left) & $1 \times 2$ & -1.43 & 0.54 & $\begin{array}{l}-2.49 \\
-0.36\end{array}$ & 0.63 & -1.39 & 0.63 & $\begin{array}{l}-2.63 \\
-0.14\end{array}$ & 0.63 & -1.13 & 0.84 & $\begin{array}{c}-2.79 \\
0.52\end{array}$ & 0.72 & -0.73 & 0.56 & $\begin{array}{c}-1.85 \\
0.38\end{array}$ & 0.86 \\
\hline $\mathrm{LCo}^{\mathrm{R}}-\mathrm{LCo}^{\mathrm{L}}$ & $1 \times 2$ & -1.42 & 0.55 & $\begin{array}{l}-2.50 \\
-0.34\end{array}$ & 0.92 & -1.45 & 0.45 & $\begin{array}{l}-2.34 \\
-0.55\end{array}$ & 0.93 & -0.09 & 1.16 & $\begin{array}{c}-2.35 \\
2.19\end{array}$ & 0.96 & -0.15 & 0.93 & $\begin{array}{c}-1.96 \\
1.67\end{array}$ & 0.97 \\
\hline $\mathrm{MCo}^{\mathrm{R}}-\mathrm{MCo}^{\mathrm{L}}$ & $1 \times 2$ & 1.99 & 0.46 & $\begin{array}{l}1.08 \\
2.89\end{array}$ & 0.76 & 2.12 & 0.43 & $\begin{array}{l}1.27 \\
2.96\end{array}$ & 0.76 & 1.34 & 0.61 & $\begin{array}{l}0.14 \\
2.53\end{array}$ & 0.86 & 1.17 & 0.48 & $\begin{array}{l}0.21 \\
2.13\end{array}$ & 0.90 \\
\hline Total & & -0.34 & & & 0.86 & -0.49 & & & 0.87 & -0.13 & & & 0.82 & -0.24 & & & 0.86 \\
\hline
\end{tabular}

AD: Average Difference; SD=Standard Deviation; CI: Confidence Interval; ICC: Intraclass correlation coefficient 
Table 2- Mean (mm) and Standard Deviation (SD) of linear measurements for dry mandibles compared to cone-beam computed tomography (CBCT) images with different voxel sizes [analysis of variance (ANOVA) for repeated measures and Dunnett's tests]

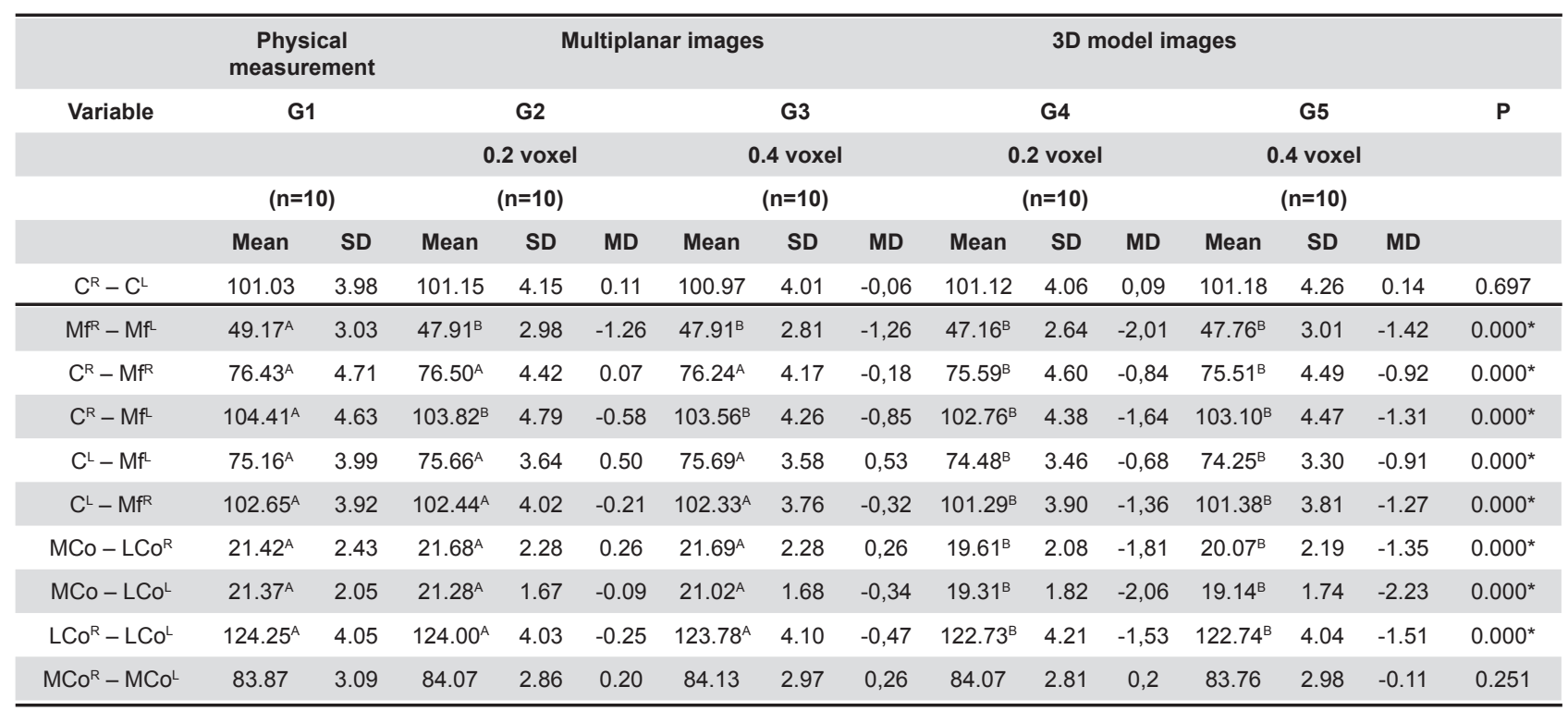

SD, Standard Deviation; MD, Mean difference

* Statistically significant

Different letters represent statistically significant differences (Dunnett's test)

\section{DISCUSSION}

CBCT maxillofacial imaging provides clinicians with an opportunity to generate $3 D$ volumetric renderings. The availability of this technology is undoubtedly expanding the use and application of 3D imaging in the field of orthodontics ${ }^{6}$. However, while CBCT provides many advantages, patient radiation dose is still higher than conventional cephalometric and panoramic digital imaging modalities ${ }^{6,29}$. This study was performed to evaluate the reliability and accuracy of linear measurements between common landmarks of the mandible taken from CBCT multiplanar sections and 3D volumetric renderings with different voxel sizes. It is not well defined if 3D model images presented accuracy. In addition, larger voxel sizes are consistent with the ALARA principle, keeping the dose as low as reasonably achievable for the intended purpose of the $\operatorname{scan}^{28}$.

Most of the previous studies ${ }^{4,12,15,18}$ performed to validate $\mathrm{CBCT}$ for $3 \mathrm{D}$ cephalometrics measured linear distances between anatomical landmarks in dry skulls in combination with radiopaque markers. Cephalometric analyses are subject to the influence of the examiner, landmark identification and type of image analyzed (2D sections or 3D image). The major question of this study was if the difficulty in identifying the landmarks in 3D images can influence the reliability and accuracy of the measurements, and for this reason, metallic markers were not used. This method is close to the real clinical procedures and is more clinically relevant than making measurements between welldefined metallic landmarks.

There was excellent intraobserver reliability for both examiners with the mean ICC for all groups above 0.95 and mean average differences less than $0.41 \mathrm{~mm}$, independently of the protocol analyzed (Table 1). Our results are in accord with similar studies that used metallic markers ${ }^{2,4,8,30}$. These differences are not clinically significant for orthodontic/surgical diagnosis and treatment planning, and acceptable for skeletal measurements ${ }^{7,16}$.

Additionally, good to high interobserver precision was identified for all groups, with exception of measurement MfR - MfL for 3D groups (Table 1 ). The main explanations for the good reliability found in this study are the use of landmarks which are easily identifiable, the calibration between observers and the high spatial definition of CBCT images. The differences between multiplanar sections and 3D volume rendering images were probably because landmarks on multiplanar images were identified on the orthogonal slices simultaneously instead of being identified directly on the surface of 3D reformatted images.

Our study also evaluated the accuracy of measurements performed in CBCT images (Table 2 ). Two variables at $\mathrm{G} 2$ and $\mathrm{G} 3$ and 8 variables at G4 and G5 were significantly smaller than physical measurements (G1). These findings were similar to those found by Lascala, et al. ${ }^{18}$ (2004) and Baumgaertel, et al. ${ }^{2}$ (2009), who showed a 
tendency for the CBCT measurements to slightly underestimate the gold standard. The consistency of the differences we found suggests a systematic error in the 3D model measurement method. One possible explanation is that this error might have been introduced by the measurement software, mainly building line. Although few software systems currently have a 3D cephalometric module, most of them have not been tested or validated ${ }^{11}$. The results of the validation measurements for a specific machine or software can not be extrapolated to the entire CBCT machine and software ${ }^{11}$. Most of them are designed differently and software updates are constant and frequent. In addition, the difference ranged from 0.06 to $2.23 \mathrm{~mm}$. In agreement with previous reports, the average difference in our study is below clinical significance. According to Grauer, et al. ${ }^{10}$ (2009), generating measurements in 3D volumetric images rather than simultaneously in sets of 2D multiplanar images introduces error because of the difficulty involved in locating landmarks in 3D space and the inaccuracies of the user entered threshold used for the construction of $3 \mathrm{D}$ virtual surface models. Rendered 3D objects may be adequate for qualitative assessment (i.e., superimposition). However, accurate quantitative assessment should still be performed on the multiplanar sections ${ }^{11}$. For this reason, greater caution is suggested for linear measurements performed on 3D models ${ }^{11}$.

The spatial resolution of the image has an influence in the accuracy of the measurements ${ }^{27}$. Most studies on CBCT with a large field of view used $0.4 \mathrm{~mm}$ voxel size $\mathrm{e}^{4,12,21}$, whereas others with a small field of view used a $0.2 \mathrm{~mm}$ or smaller voxel sizes ${ }^{15,26}$. None of the measurements showed significant difference between the voxel sizes, independently of the method of measurement (Table 2). These results are in accord with those of Ballrick, et al. ${ }^{1}$ (2008) and Damstra, et al. ${ }^{8}$ (2010), who have suggested that $0.4 \mathrm{~mm}$ voxel resolution is adequate for performing measurements of craniofacial structures. While small voxel sizes increase the image resolution, they also may increase the image noise ${ }^{22}$. The benefits of a shorter scanning time, with its reduced likelihood of patient movement and especially the lower exposure dose compensates for the poorer resolution. Besides, large measurements are less influenced by small differences in spatial resolution ${ }^{22}$. On the other hand, the diagnostic ability of CBCT images for evaluating small structures appears to be influenced by voxel size. The two most common voxel sizes used in orthodontics -0.3 and $0.4 \mathrm{~mm}$ - provide lower spatial resolution than smaller voxel sizes. Orthodontic scans with resolutions of 0.3 and 0.4 voxels are ideal for general treatment planning but should be used with caution if the goal is to assess small variations in bone thickness ${ }^{22}$. Liedkte, et al. $^{19}$ (2009) investigated the usefulness of CBCT for identifying artificial external root resorption in images with voxel sizes of $0.4,0.3$, and $0.2 \mathrm{~mm}$. They concluded that, even though the results were the same for the different voxel sizes, diagnosis was easier at smaller voxel sizes of 0.3 and 0.2 $\mathrm{mm}$. Although the benefits of a shorter scanning time satisfy the "as low as reasonably achievable" principle, the risks of misdiagnosis and treatment complications must also be weighed. Consequently, a scanning protocol with a $0.40 \mathrm{~mm}$ voxel size might not be suitable for every patient. Voxel size may vary according to the size of the structures to be analyzed as well as to the level of detail desired. In this study, we measured distances that are in excess of the resolutions 0.2 and $0.4 \mathrm{~mm}$ of the scan, so that voxel size would not very likely influence the measurements.

Three-dimensional cephalometric analysis is much more time-consuming. Unlike in conventional cephalometrics, where all the landmarks are identified in one image, namely, the lateral cephalogram, with CBCT each landmark must be identified in three different images (axial, coronal and sagittal), making the process of performing the measurements in CBCT images more timeconsuming for the orthodontist. Further, CBCT demands a higher radiation dose than traditional cephalometric images. For these reasons, its use should be limited to specific indications, for example, patients with impacted teeth, or those with facial asymmetries or craniofacial anomalies where $\mathrm{CBCT}$ is better able to quantify the differences between the right and the left side of craniofacial structures. Evidence-based will tell whether future advances, especially in terms of dose reduction, will make CBCT appropriate for routine use in all orthodontic patients.

\section{CONCLUSIONS}

Linear measurements obtained on multiplanar 2D CBCT images with 0.2 and 0.4 voxel sizes using i-Cat scanner and Dolphin ${ }^{\circledR}$ software are reliable and accurate for clinical diagnosis and treatment planning.

Caution should be taken in linear measurements on $3 \mathrm{D}$ rendering images, because the measurements were reliable, but not accurate.

Reducing the voxel size from 0.4 to $0.2 \mathrm{~mm}$ does not influence the accuracy and reliability of measurements of large craniofacial structures on CBCT-3D images. 


\section{REFERENCES}

1- Ballrick JW, Palomo JM, Ruch E, Amberman BD, Hans MG. Image distortion and spatial resolution of a commercially available conebeam computed tomography machine. Am J Orthod Dentofacial Orthop. 2008;134(4):573-82.

2- Baumgaertel S, Palomo JM, Palomo L, Hans MG. Reliability and accuracy of cone-beam computed tomography dental measurements. Am J Orthod Dentofacial Orthop. 2009;136(1):1925.

3- Baumrind S, Frantz RC. The reliability of head film measurements. 1. Landmark identification. Am J Orthod. 1971;60(2):111-27.

4- Berco M, Rigali PH Jr, Miner RM, DeLuca S, Anderson NK, Will LA. Accuracy and reliability of linear cephalometric measurements from cone-beam computed tomography scans of a dry human skull. Am J Orthod Dentofacial Orthop. 2009;136(1):17e1-9.

5- Bogdanich W, McGinty JC. Radiation worries for children in dentists' chairs [online]. The New York Times. 2010 Nov. 22 [cited 2013 Sep. 3]. Available from: http://www.nytimes. com/2010/11/23/us/23scan.html?pagewanted=all\&_r=0.

6- Brown AA, Scarfe WC, Scheetz JP, Silveira AM, Farman AG. Linear accuracy of cone beam CT derived 3D images. Angle Orthod. 2009;79(1):150-7.

7- Cavalcanti MG, Haller JW, Vannier MW. Three-dimensional computed tomography landmark measurement in craniofacial surgical planning: experimental validation in vitro. J Oral Maxillofac Surg. $1999 ; 57(6): 690-4$

8- Damstra J, Fourie Z, Huddleston Slater JJ, Ren Y. Accuracy of linear measurements from cone-beam computed tomographyderived surface models of different voxel sizes. Am J Orthod Dentofacial Orthop. 2010;137(1):16 e1-6.

9- Friedland B, Donoff B, Dodson TB. The use of 3-dimensional reconstructions to evaluate the anatomic relationship of the mandibular canal and impacted mandibular third molars. J Oral Maxillofac Surg. 2008;66(8):1678-85.

10- Grauer D, Cevidanes LS, Proffit WR. Working with DICOM craniofacial images. Am J Orthod Dentofacial Orthop. 2009;136(3):460-70.

11- Gribel BF, Gribel MN, Frazão DC, McNamara JA Jr, Manzi FR. Accuracy and reliability of craniometric measurements on latera cephalometry and 3D measurements on CBCT scans. Angle Orthod. 2011;81(1):26-35.

12- Hilgers ML, Scarfe WC, Scheetz JP, Farman AG. Accuracy of linear temporomandibular joint measurements with cone beam computed tomography and digital cephalometric radiography. Am J Orthod Dentofacial Orthop. 2005;128(6):803-11.

13- Houston WJ. The analysis of errors in orthodontic measurements. Am J Orthod. 1983;83(5):382-90.

14- Kau CH, Richmond S, Palomo JM, Hans MG. Three-dimensional cone beam computerized tomography in orthodontics. J Orthod. 2005;32(4):282-93.

15- Kobayashi K, Shimoda S, Nakagawa Y, Yamamoto A. Accuracy in measurement of distance using limited cone-beam computerized tomography. Int J Oral Maxillofac Implants. 2004;19(2):228-31. 16- Kragskov J, Bosch C, Gyldensted C, Sindet-Pedersen S. Comparison of the reliability of craniofacial anatomic landmarks based on cephalometric radiographs and three-dimensional CT scans. Cleft Palate Craniofac J. 1997;34(2):111-6.
17- Lamichane M, Anderson NK, Rigali PH, Seldin EB, Will LA. Accuracy of reconstructed images from cone-beam computed tomography scans. Am J Orthod Dentofacial Orthop. $2009 ; 136(2): 156-7$

18- Lascala CA, Panella J, Marques MM. Analysis of the accuracy of linear measurements obtained by cone beam computed tomography (CBCT-NewTom). Dentomaxillofac Radiol. 2004;33(5):291-4.

19- Liedke GS, Silveira HE, Silveira HL, Dutra V, Figueiredo JA. Influence of voxel size in the diagnostic ability of cone beam tomography to evaluate simulated external root resorption. J Endod. 2009;35(2):233-5.

20- Lou L, Lagravere MO, Compton S, Major PW, Flores-Mir C. Accuracy of measurements and reliability of landmark identification with computed tomography (CT) techniques in the maxillofacial area: a systematic review. Oral Surg Oral Med Oral Pathol Oral Radiol Endod. 2007;104(3):402-11.

21- Ludlow JB, Laster WS, See M, Bailey LJ, Hershey HG. Accuracy of measurements of mandibular anatomy in cone beam computed tomography images. Oral Surg Oral Med Oral Pathol Oral Radiol Endod. 2007;103(4):534-42.

22- Molen AD. Considerations in the use of cone-beam computed tomography for buccal bone measurements. Am J Orthod Dentofacial Orthop. 2010;137:S130-5.

23- Moreira CR, Sales MA, Lopes PM, Cavalcanti MG. Assessment of linear and angular measurements on three-dimensional conebeam computed tomographic images. Oral Surg Oral Med Oral Pathol Oral Radiol Endod. 2009;108(3):430-6.

24- Navarro RL, Oltramari-Navarro PV, Fernandes TM, Oliveira GF, Conti AC, Almeida MR, et al. Comparison of manual, digital and lateral CВCT cephalometric analyses. J Appl Oral Sci. 2013;21(2):167-76.

25- Oliveira-Santos C, Capelozza AL, Dezzoti MS, Fischer CM, Poleti ML, Rubira-Bullen IR. Visibility of the mandibular canal on CBCT cross-sectional images. J Appl Oral Sci. 2011;19(3):240-3. 26- Pinsky HM, Dyda S, Pinsky RW, Misch KA, Sarment DP. Accuracy of three-dimensional measurements using cone-beam CT. Dentomaxillofac Radiol. 2006;35(6):410-6.

27- Scarfe WC, Farman AG, Sukovic P. Clinical applications of cone-beam computed tomography in dental practice. J Can Dent Assoc. 2006;72(1):75-80.

28- SEDENTEXCT Project. Radiation protection: Cone beam CT for dental and maxillofacial radiology. Evidence based guidelines [online]. 2011 [cited September 3, 2013]. Available from: http:// www.eadmfr.info/sites/default/files/guidelines_final.pdf.

29- Silva MA, Wolf $U$, Heinicke F, Bumann A, Visser $H$, Hirsch E. Cone-beam computed tomography for routine orthodontic treatment planning: a radiation dose evaluation. Am J Orthod Dentofacial Orthop. 2008;133(5):640.e1-5.

30- Tomasi C, Bressan E, Corazza B, Mazzoleni S, Stellini E, Lith A. Reliability and reproducibility of linear mandible measurements with the use of a cone-beam computed tomography and two object inclinations. Dentomaxillofac Radiol. 2011;40(4):244-50. 